\title{
Neck Vessel Dissection following Whiplash-Type Neck Injury
}

\section{Richard Peatfield, MD, Harri Jenkins, MD}

Department of Neurology, Charing Cross Hospital, London W6 8RF, UK. Richard.Peatfield@nhs.net

*Corresponding Author: Richard Peatfield MD, Department of Neurology, Charing Cross Hospital, London, UK.

\section{Abstract}

A systematic audit has found that 14 of 179 patients with complex whiplash neck injuries had features suggesting thromboembolism, which we presume originated from an arterial dissection in the neck. Most made a reasonable recovery. Until prospective studies from Emergency Departments are available a short period of prophylactic aspirin should be considered in all patients with acute neck injuries.

\section{INTRODUCTION}

Most patients seeking compensation for whiplash-type neck injuries complain only of neck pain, which usually resolves over a few months, though occasionally this takes longer. Dissections of the carotid or vertebral arteries in the neck have been reported in such injuries; we have done a systematic audit of whiplash cases to estimate the frequency of arterial dissections in complex personal injury patients.

Table

\begin{tabular}{|c|c|c|c|c|c|c|c|}
\hline & Age & & Risk factors & & $\begin{array}{l}\text { Delay } \\
\text { (days) }\end{array}$ & Symptoms & Resolution \\
\hline 1 & 34 & $\mathrm{~F}$ & HT & Rear RTA & 22 & L Hemiparesis & Poor \\
\hline 2 & 55 & M & & Rear RTA & Instantaneous & R Hemiparesis & Incomplete \\
\hline 3 & 34 & M & & Rear RTA & 7 & L Hemiparesis & Persisting \\
\hline 4 & 47 & $\mathrm{~F}$ & & Hit by door & 41 & R Hemiparesis & Improved \\
\hline 5 & 28 & $\mathrm{~F}$ & $\begin{array}{l}\text { Progestogen } \\
\text { only pill }\end{array}$ & Rear RTA & Instantaneous & L Hemiparesis & Improved \\
\hline 6 & 33 & $\mathrm{~F}$ & & Side RTA & 1 & R paraesthesiae & Min disability \\
\hline 7 & 30 & M & & Rear RTA & 2 & Unsteady & Min disability \\
\hline 8 & 47 & $\mathrm{~F}$ & $\begin{array}{l}\text { Old Idiopathic } \\
\text { Intracranial } \\
\text { Hypertension }\end{array}$ & Side RTA & Instantaneous & L paraesthesiae & Min disability \\
\hline 9 & 55 & $\mathrm{~F}$ & HT & Rear RTA & Instantaneous & L facial numbness & Min disability \\
\hline 10 & 34 & $\mathrm{~F}$ & $\begin{array}{l}\text { HT RVD } \\
\text { Diabetic }\end{array}$ & Rear RTA & Instantaneous & R temporal defect & Min disability \\
\hline 11 & 33 & M & & Rear RTA & 10 minutes & $\begin{array}{l}\text { R facial \& limb } \\
\text { numbness; } \\
\text { vomiting; vertigo }\end{array}$ & Improved \\
\hline
\end{tabular}

In the last four years we have prepared medicolegal reports on a total of 220 patients with whiplash-like neck pain, mainly after rear-end traffic collisions. Of these 197 had only neck pain, 9 had radiculopathic symptoms as well, and 14 had symptoms and signs suggesting that they had experienced an arterial dissection of a neck vessel with presumed secondary thromboembolism. 
Neck Vessel Dissection following Whiplash-Type Neck Injury

\begin{tabular}{|l|l|l|l|l|l|l|l|}
\hline 12 & 46 & F & & Rear RTA & 1 & $\begin{array}{l}\text { R paraesthesiae; } \\
\text { dysphasia }\end{array}$ & Min disability \\
\hline 13 & 29 & M & & Complex RTA & Instantaneous & $\begin{array}{l}\text { R paraesthesiae \& } \\
\text { weakness }\end{array}$ & Min disability \\
\hline 14 & 40 & F & & Rear RTA & 2 & $\begin{array}{l}\text { R paraesthesiae; } \\
\text { dysphasia; poor } \\
\text { memory }\end{array}$ & Min disability \\
\hline
\end{tabular}

\section{CASE Histories}

Case 1 A 34 year old woman with a 4 year history of treated hypertension, who slipped and fell when a bus braked suddenly, striking her head on the bus floor; she recovered quickly and did notseek medical advice. Three weeks later, when in a shop talking to a friend, she suddenly fell to the floor, lost consciousness and vomited. There was a period of amnesia of at least two hours. She was found to have a left hemiparesis affecting the arm much more than the leg. A CT brain scan demonstrated a right thalamic haemorrhage and a lacunar infarct in the right external capsule; a CT venogram was normal. She has made a reasonable functional recovery, though she had been left with a marked left hemiparesis, much worse in the arm than the leg. [Fig 1]

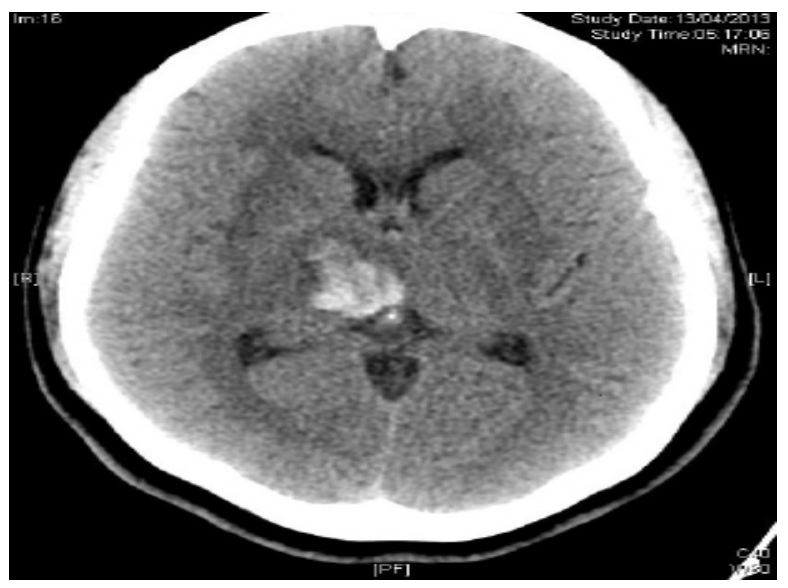

Case 2 A 55 year old man who was a front seat passenger involved in a rear end collision. He can recall a sharp pain in his neck, and immediately losing all feeling in the right hand, arm and right leg. The right arm seemed to shake, and for a while he could not move it. Routine hospital investigations of his neck proved normal, and he was not offered a specific diagnosis. When assessed 15 months later he had a weak, numb right arm and right leg. He was able to walk indefinitely though he has problems getting out of a car, and has tended to fall over. He was unable to write more than 3-4 lines before the pen fell out of his hand.

Case 3 A 34 year old man involved in a rear-end collision at about $30 \mathrm{mph}$. He experienced neck pain at once. About a week later he suddenly developed numbness in the left leg, extending up to the buttocks anteriorly, and close to but not reaching the anal margin posteriorly. This caused him to walk with a limp, and he had a very slight left foot drop. His arms, bladder and bowels were unaffected. He was reviewed in hospital, but no explanation was offered. After 9 months the residual disability was minimal.

Case 4 A 47 year old woman who was struck in the centre of the forehead by a heavy-duty fire door. She was knocked to the ground, and thinks she was unconscious for a few seconds. Six weeks later she suddenly became much worse over an hour, with worsening of the headache and the evolution of rightsided weakness, affecting both the right arm and right leg. She had another CT brain scan, which was considered normal, as well as a lumbar puncture. She was discharged without a clear diagnosis. An MRI brain scan six months after the accident demonstrated a $5 \times 4 \mathrm{~mm}$ high signal area on T2 images in the right cerebellar hemisphere. [Fig 2] On assessment 10 months later there was a definite right hemiparesis affecting the arm and leg equally. Her arm reflexes were all brisker on the right, with an extensor plantar response on the right. Sensation was normal.

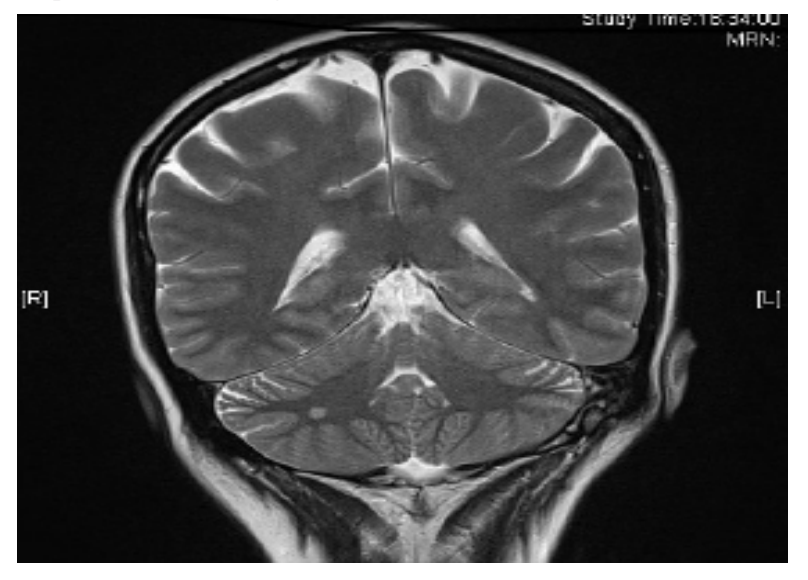


Case 5 A 28 year old woman involved in a concertina rear end collision. Within 5-10 minutes she was unable to move her left arm and left leg. Her left leg recovered over a week, but definite residual weakness remains in the left arm, though this has been improving gradually. She also has a sensory disturbance in the left hand, the left side of her face and the left trunk with paraesthesiae and an illdefined feeling that insects were crawling over the skin, particularly when lying in bed at night, and she had noted her speech to be a little slurred. A CT brain scan some three months after the accident was reported as normal.

Case 6 A 33 year old woman involved in a side-on collision. The car roof fell onto her head and she was rendered unconscious for 20 seconds. She had particularly severe pain in her neck immediately after the accident. The following day she developed paraesthesiae in the right side of her face and the right arm. An emergency MRI brain scan showed no abnormality. After 15 months the paraesthesiae did not cause any real disability.

Case 7 A 30 year old man who was involved in a rearend collision 'at speed'. He had some pain in his neck which persisted for about two weeks, and did not recur. The evening after the accident he developed a severe bifrontal headache, and when he returned to work the next day he noted an instability on his feet, "as if drunk", without any true vertigo or disturbances of hearing. There were no positional features. The symptoms remained "quite severe" for two weeks, and have gradually improved, though he was left with instability at about " $20 \%$ " of its maximum at its peak during that first week. His symptoms were never further investigated. Two years later his disabilities were minimal.

Case 8 A 47 year old woman who was a front seat passenger involved in a side impact collision, level with her door. Immediately after the accident the whole of the left side of her body (though perhaps not the head) started 'fizzing'. This lasted for two days, and has not recurred. The morning after the accident she developed twitching and numbness on the left side of her face, level with her mouth, which continued for 2 months. There were no physical signs when she was assessed 9 months later.

Case 9 A 55 year old woman who was involved in a rear-end collision. She felt her head going "backwards and forwards" hitting the headrest in the left parietal area, and there was an immediate severe pain at the site of this impact and in her neck. She felt dazed, and took a few minutes to recover. She was left with a numb feeling on the left side of her face, which she said started whilst she was still in the car. This was intermittent occurring for between a few hours and 24 hours between twice monthly and twice weekly. The area involved was largely in front of the left ear, involving the ophthalmic, maxillary and mandibular divisions of the nerve, but not extending even as far as the centre of her zygoma vertically below the eye. There had been little change in the symptoms since its onset. There were no neurological signs, and she admitted that she was not disabled.

Case 10 A 34 year old woman who was known to be hypertensive and a borderline diabetic and had a degree of asymptomatic right ventricular dilatation. She experienced a rear-end collision at an estimated speed of $50 \mathrm{mph}$. She can recall violent neck movements, and onlookers noted that she was holding her neck. Immediately after the accident she noted that her vision was blurred. An optometrist demonstrated an upper temporal quadrantic field effect, only in the right eye. A CT brain scan after 6 months, and an MRI brain scan with arteriographic views of the neck vessels done after 2 years, as well as her visual evoked responses, were normal. With new glasses she had no significant visual symptoms. She has also noticed an ill-defined sensory disturbance on the right side of her face since the accident, which had changed very little. On examination there was no demonstrable field defect on confrontation. Sensory testing with a pin induced an abnormal tingling sensation in the maxillary and mandibular divisions of the trigeminal nerve on the right, but not on the forehead on either side.

Case 11 A 33 year old right-handed chef who was involved in a rear-end collision at speed; he could recall both neck and lumbar pain at the time. He did not go to hospital; within ten minutes he started vomiting profusely out of the window of his car, and he had a very severe right hemicranial headache. He realised he had numbness and paraesthesiae affecting the right side of his face, the right arm and the right leg, including his foot, as well as severe vertigo. He had normal CT brain and cervical spine scans, and a diagnosis of "concussion" was made. He was allowed home the same evening. The vomiting only lasted an 
hour and the vertigo two or three days - during this time he was unable to walk unsupported. In contrast the weakness, numbness and paraesthesiae on the right side of his body have remained relatively stable. He tends to drop heavy things in his kitchen, and has great difficulty wet shaving, as he has no perception of the blade on the right side of his face. He has difficulty judging the consistency of a steak with his right hand as it cooks. On examination there was definite facial numbness to the right, particularly to pin and temperature sensation. There was only a minimal pronator drift on the right, with a possible weakness of the right hand, but this was still stronger than the left. Co-ordination was normal. His right knee jerk was a little brisker than the left. There was definite dullness to pin perception over the whole of the right side, including his head and scalp. Proprioception was accurate, but slower in both the right hand and foot, and cold perception was abnormal on the right. Vibration sense seemed normal.

Case 12 A 46 year old right-handed woman who was involved in a rear-end collision "at speed"; enough to write off her car. She was jolted backwards and forwards, and her glasses flew off. She visited her General Practitioner the next day because of generalised aching and nausea, and the development of paraesthesiae and some weakness in the right hand, with difficulty speaking. She was reassured and given analgesics. The paraesthesiae in the right hand, the weakness of grip and particularly the dysphasia were troublesome for about two months, but then settled down, though she is still left with a stable deficit - she has a little difficulty opening new jars of jam, and she occasionally makes dysphasic errors, particularly when speaking in public. On examination her speech seemed normal, and there were no other signs.

Case 13 A 29 year old man who was driving on a congested motorway; traffic was permitted to drive on the hard shoulder. When the hard shoulder ended a lorry driver pulled back onto the main carriageway without signalling, striking the rear of his car. It spun in front of the lorry and was pushed along for some distance before being pushed off the road, striking the crash barrier and spinning twice more. Immediately after the accident his neck pain was accompanied by some paraesthesiae affecting his right arm, right shoulder and right leg, which lasted for two or three days. There was also some ill-defined tingling and pain on the left side of the jaw, which has improved slowly, though incompletely. He admitted that they are not disabling. Apart from some restriction of lateral flexion of his neck there were no abnormalities on examination.

Case 14 A 40 year old woman who was involved in a rear-end collision at speed. She sustained neck pain at the time, together with a bad generalised headache. Two days after the impact the headache became very much worse with vomiting, and she developed paraesthesiae in the right hand and some difficulty with her memory - she could not remember the way to work in the car, or indeed whether she had fed her children. Her speech was a little slurred. The symptoms were bad for a day and slowly improved the right hand recovered after about seven days, but the memory disturbance took at least a month. Her General Practitioner arranged a CT brain scan which was undertaken six weeks after the accident. This shows small bilateral hypointensities in the lentiform nuclei which were thought to be normal perivascular spaces. Apart from gross restriction of both lateral and anteroposterior flexion of her neck there were no abnormalities on examination.

\section{DisCUSSION}

This series cannot be considered representative of whiplash cases as a whole, as only the more severe and complex patients seeking compensation are referred for consultant assessment.

In all these cases the presence of a dissection is necessarily conjectural, though many of the patients are young, without conventional vascular risk factors. It is unusual for the patients to be fully investigated at the time they develop focal symptoms, and they are only seen as part of their injury claim months or sometimes years afterwards, when the artery may have recanalised, and normal findings, including vascular imaging (eg. case 10), cannot exclude a dissection. The legal concept of the 'balance of probabilities' would seem applicable. Arterial dissection is a recognised complication of neck manipulation [1,2], and neck trauma[3], and dissections have been recorded even after minor trauma such as hyperextending the neck at the hairdressers [4,5].

Recent evidence suggests that the rate of thrombotic complications in neck arterial dissection is low. The multicentre CADISS trial [6] randomised recently symptomatic patients to treatment with either 
antiplatelet drugs or anticoagulants. As well as demonstrating no difference in outcomes between the two treatments, it showed that the incidence of stroke in the 3 months after randomisation was only $2 \%$.

All our cases had focal symptoms, and they could therefore represent the tip of a dissection 'iceberg' -there may be a lot of whiplash victims with unrecognised dissections that cause only pain. We suggest that the incidence of arterial dissection in whiplash should be investigated by a prospective study of patients attending Accident and Emergency departments with some non-invasive vascular imaging.

The patients are usually seen in an Accident and Emergency department soon after the accident. Before we know the true prevalence of dissections, we wonder if the administration of aspirin to every whiplash patient in the acute phase might serve to lower the possibility of thrombotic complications, at minimal risk.

\section{REFERENCES}

[1] Ernst E Adverse effects of spinal manipulation: a systematic review J R Soc Med 2007 100 330-338.
[2] Biller J et al Cervical Arterial Dissections and Association With Cervical Manipulative Therapy. A Statement for Healthcare Professionals from the American Heart Association/American Stroke Association. Stroke 201445 3155-3174.

[3] Thomas LC, Rivett DA, Parsons M, Levi C Risk factors, radiological features, and infarct topography of craniocervical arterial dissection. International Journal of Stroke 20149 10731082.

[4] Nwokolo N, Bateman DE Stroke after a visit to the hairdresser. Lancet 1997350866

[5] BBC news 12 December 2016 www.bbc.co.uk/ news/health-38287938. Last accessed February 2018.

[6] Antiplatelet treatment compared with anticoagulation treatment for cervical artery dissection (CADISS): a randomised trial The Lancet Neurology 201514 361-367

Citation: Richard Peatfield, Harri Jenkins. Neck Vessel Dissection following Whiplash-Type Neck Injury. Archives of Emergency Medicine and Intensive Care. 2018; 1(1): 22-26.

Copyright: (c) 2018 Richard Peatfield, Harri Jenkins. This is an open access article distributed under the Creative Commons Attribution License, which permits unrestricted use, distribution, and reproduction in any medium, provided the original work is properly cited. 